\title{
Organisational downsizing and musculoskeletal problems in employees: a prospective study
}

\author{
M Kivimäki, J Vahtera, J E Ferrie, H Hemingway, J Pentti
}

\begin{abstract}
Objectives-To study the association between organisational downsizing and subsequent musculoskeletal problems in employees and to determine the association with changes in psychosocial and behavioural risk factors.

Methods-Participants were 764 municipal employees working in Raisio, Finland before and after an organisational downsizing carried out between 1991 and 1993. The outcome measures were self reports of severity and sites of musculoskeletal pain at the end of 1993 and medically certified musculoskeletal sickness absence for 1993-5. The contribution of changes in psychosocial work characteristics and health related behaviour between the 1990 and 1993 surveys was assessed by adjustment.

Results-After adjustment for age, sex, and income, the odds ratio (OR) for severe musculoskeletal pain between major and minor downsizing and the corresponding rate ratios for musculoskeletal sickness absence were 2.59 (95\% confidence interval $(95 \% \mathrm{CI}) 1.5$ to 4.5$)$ and 5.50 (3.6 to 7.6), respectively. Differences between the mean number of sites of pain after major and minor downsizing was 0.99 (0.4 to 1.6). The largest contribution from changes in work characteristics and health related behaviour to the association between downsizing and musculoskeletal problems was from increases in physical demands, particularly in women and low income employees. Additional contributory factors were reduction of skill discretion (relative to musculoskeletal pain) and job insecurity. The results were little different when analyses were confined to
\end{abstract} initially healthy participants.

Conclusions-Downsizing is a risk factor for musculoskeletal problems among those who remain in employment. Much of this risk is attributable to increased physical demands, but adverse changes in other psychosocial factors may also play a part.

(Occup Environ Med 2001;58:811-817)

Keywords: ocupational health; musculoskeletal disorders; downsizing

Organisational downsizing (reduction of personnel by businesses and other organisations) has become an important aspect of modern working life. ${ }^{12}$ In the United States, for example, 43 million jobs were erased between 1979
Main messages

- Earlier research on the health effects of organisational downsizing has paid little attention to development of musculoskeletal disorders.

- Downsizing is a risk factor for musculoskeletal problems among those who remain in employment.

- This risk involves men and women irrespective of socioeconomic status. The effect was stronger in those with preexisting musculoskeletal problems, but was also found in initially healthy employees.

- Much of the adverse effect of downsizing on musculoskeletal health is attributable to increasing work demands arising from work force reductions.

- Adverse changes in other psychosocial factors-such as job control and job insecurity-may also contribute to musculoskeletal morbidity after downsizing.

Policy implications

- Those making decisions about organisational downsizing should be aware of the potential negative consequences of this managerial strategy to health of employees.

- Measures to prevent increasing numbers of musculoskeletal problems among staff may decrease excess morbidity relative to downsizing.

- Heightened work demands seems to be a main contributor to the association between downsizing and musculoskeletal problems.

and 1995, and in one third of all households, a family member had been laid off during this period. ${ }^{2}$ Downsizing can be a risk to the health of those who remain in employment. ${ }^{3-7}$ However, there is a lack of studies investigating potential psychosocial and behavioural mechanisms linking downsizing and health outcomes.

Musculoskeletal problems are among the most common causes of disability in workers across occupational groups. ${ }^{8-11}$ There is also a rising trend in work related musculoskeletal problems. ${ }^{12} 13$ The aetiology of musculoskeletal disorders is multifactorial. ${ }^{14-23}$ Risk factors include high work demands, job insecurity, low job control, smoking, and vigorous exercise. These factors have also been associated with 
downsizing or organisational restructuring. ${ }^{74} 25$ Sickness absence records are important indicators of health in working populations and an association between downsizing and musculoskeletal sickness absence has already been found. ${ }^{56}$ However, sickness absence for musculoskeletal problems may be influenced by the physical demands of the job, the severity of disability, and the culture of absence behaviour. Self reports of musculoskeletal problems do not face such work based constraints. As far as we are aware, no previous study on downsizing has considered both self reported and record based outcomes.

The longitudinal Raisio study is uniquely able to investigate associations between downsizing, changes related to work and other areas of life, and musculoskeletal problems. It focused on municipal staff in the service of the Finnish town of Raisio before and after the most severe economic decline in Finland since the first world war. Unemployment rose from $3 \%$ in 1990 to $16 \%$ in 1993 and was still $15 \%$ in $1995 .{ }^{27}$ The average reduction of days worked in Raisio was 15\% between 1991 and 1993 but there was considerable variation between occupational groups. ${ }^{57}$ Only a slight (4\%) increase in days worked between 1993 and 1995 followed the downsizing.

The objectives of this study were $(a)$ to determine the association between downsizing and musculoskeletal problems, measured with self reported and sickness absence data, and $(b)$ to identify psychosocial and behavioural mechanisms underlying this association. We hypothesised that such mechanisms may include increased work demands, high job insecurity, and loss of job control. Furthermore, we tested whether smoking and vigorous exercise, as attempts at coping, may increase the likelihood of musculoskeletal problems relative to downsizing.

\section{Methods}

PARTICIPANTS

The cohort was the same as that used in our previous study of downsizing. ${ }^{7}$ It comprised 189 male and 575 female municipal employees who had responded in 1990 and 1993 to surveys designed to assess characteristics of work, social relations, and health related behaviour. Participants represented $78 \%$ of the eligible population - that is, those permanent, full time, Raisio employees in continuous employment for at least 6 months in both 1991 and 1993. The mean age was 41 (range 20-62) in men and 42 (range 21-60) years in women. Twenty nine per cent were higher grade white collar workers (managers, physicians, teachers), $45 \%$ lower grade white collar workers (technicians, registered nurses, office workers), and $26 \%$ blue collar workers (cleaners, maintenance workers, kitchen assistants). Data covered 936 person-years of follow up for men and 2800 person-years of follow up for women during the 5 year study period from 1991 to 1995.

Participants were representative of the eligible population from which they did not differ in terms of age (41 years in both groups), sex ( $75 \%$ and $73 \%$ women respectively), socioeconomic status $(76 \%$ white collar and $26 \%$ blue collar workers in both groups), and musculoskeletal sickness absence (mean rate 17.5 and 17.2 spells/100 years respectively).

\section{DESIGN}

We obtained baseline information about severity and sites of musculoskeletal pain, psychosocial work characteristics, and health related behaviour from a survey in 1990. Baseline musculoskeletal sickness absences were derived from the 1991 records. Exposure to downsizing was indicated from reduction of days worked in each job category between 1991 and 1993. Outcomes were severity of musculoskeletal pain and sites of musculoskeletal pain, measured by a survey carried out in November 1993, and musculoskeletal sickness absences obtained from records related to the years 1993 to 1995 . Potential contributors to the association between downsizing and these outcomes included changes in psychosocial work characteristics and health related behaviour measured by the two surveys in 1990 and 1993 (box).

\section{DOWNSIZING}

We constructed an ecological measure of the extent of downsizing during the 3 years in each of the job categories in which the respondents worked. ${ }^{57}$ Information obtainable from the employer's records for all periods included dates of starting work, and where appropriate, ending work; job titles; and dates on which

\begin{tabular}{|c|c|c|}
\hline \multicolumn{3}{|l|}{ Study design } \\
\hline Year & Measurements & Source of data \\
\hline $\begin{array}{l}\text { 1990-1 } \\
\text { (baseline information) }\end{array}$ & $\begin{array}{l}\text { Demographics } \\
\text { Work characteristics and health behaviour } \\
\text { Musculoskeletal pain } \\
\text { Sickness absence due to musculoskeletal disorders }\end{array}$ & $\begin{array}{l}\text { Employer's records (1990-1) } \\
\text { Survey (November 1990) } \\
\text { Survey (November 1990) } \\
\text { Records from occupational healthcare unit } \\
\text { (1 January-31 December 1991) }\end{array}$ \\
\hline $\begin{array}{l}\text { 1991-3 } \\
\text { (downsizing) }\end{array}$ & Reduction in the sum of days worked in different job categories ${ }^{\star}$ & $\begin{array}{l}\text { Employer's records (1 January-31 December } \\
1991 \text { and } 1 \text { January-31 December 1993) }\end{array}$ \\
\hline $\begin{array}{l}1993-5 \\
\text { (explanatory factors and } \\
\text { outcome variables) }\end{array}$ & $\begin{array}{l}\text { Work characteristics and health behaviour } \\
\text { Musculoskeletal pain } \\
\text { Sickness absence due to musculoskeletal disorders }\end{array}$ & $\begin{array}{l}\text { Survey (November 1993) } \\
\text { Survey (November 1993) } \\
\text { Records from occupational healthcare unit } \\
\text { (1 January-31 December 1995) }\end{array}$ \\
\hline
\end{tabular}


each period of absence began and ended. We calculated the number of days worked by subtracting days equivalent to number of days off work, irrespective of cause, from total possible working days, for each job category in 1991 and in 1993. Job categories were based on the classification of occupations by Statistics Finland (32 occupational groups). Percentage reductions in the number of days worked from 1991 to 1993 were calculated for each job category, as a measure of the extent of downsizing. Categories of minor $(<8 \%)$, intermediate $(8 \%-18 \%)$ and major ( $>18 \%)$ downsizing were used as in our earlier study on all cause absence in the same cohort. ${ }^{7}$ Categories of minor and major downsizing also corresponded with those used in the previous study on the eligible population. ${ }^{5}$ A more detailed description of the measure is given elsewhere. ${ }^{5}$

\section{MUSCULOSKELETAL PROBLEMS}

Three indicators of musculoskeletal problems were used: (a) status of severe musculoskeletal pain; (b) number of sites of musculoskeletal pain; and (c) number of recorded spells of musculoskeletal sickness absence.

Assessment of severe musculoskeletal pain was based on a visual analogue scale. ${ }^{28}$ Participants indicated the intensity of such pain on a $100 \mathrm{~mm}$ line by placing a mark between statements of "no pain" and "the greatest imaginable pain" during the past 7 days. A dichotomous measure of severe pain identified cases from marks $55 \mathrm{~mm}$ or less from the ultimate pain end. This cut off point is $15 \%$ tighter than that used to detect pain in previous research ${ }^{29}$ and allows enough cases to examine the effect of downsizing on severe pain in the present cohort.

The number of sites of musculoskeletal pain was measured by the Nordic musculoskeletal questionnaire. ${ }^{30}{ }^{31}$ It asks about problems, such as ache, pain, and discomfort, arising in nine body areas (neck, shoulders, elbows, wrists or hands, upper back, lower back, hips or thighs or buttocks, knees, and ankles or feet). A continuous measure of the number of reported sites of pain during the past 12 months in the 1993 survey was the outcome (range $0-9$ ). Initially healthy cohort was defined as those with no reported sites of musculoskeletal pain during the past 7 days in the 1990 survey.

Earlier research shows that organisational downsizing increases the risk of medically certified sickness absence but not self certified sickness absence. ${ }^{5}$ Thus, this paper deals with medically certified absences relating to all those diagnoses which belong to the main category of musculoskeletal disorders in the international classification of diseases (ICD), 1977 revision. $^{32}$ Illustrative diagnoses are osteoarthritis, rheumatoid arthritis, sciatica, and lumbago. We grouped all periods of musculoskeletal sickness absence that occurred before downsizing in 1991 and all such periods that occurred after downsizing in 1993-5. We checked records for inconsistencies, and combined any overlapping or consecutive periods of sickness absence.
Data on sick leaves were collected from computer based records kept by the Raisio occupational healthcare unit. They include data for each employee on when sick leave began and ended and the diagnosis in coded form. All certificates relating to sick leaves, irrespective of place of issue, had to be forwarded for recording. For periods of absence of up to 3 days, employees could complete their own certificates. Such absences were not included in the present study. For absences of more than 3 days, which were the focus of this study, medical certificates are required.

The three indicators of musculoskeletal problems were moderately interrelated (Pearson correlation between self reported indicators $\mathrm{r}=0.45$; correlations of severity and number of sites of musculoskeletal pain to musculoskeletal sickness absence were 0.31 and 0.32 , respectively, $\mathrm{p}<0.001$ in all cases).

POTENTIAL EXPLANATORY FACTORS

We used information obtained by questionnaire surveys in 1990 and 1993 about those adverse changes in characteristics of work and health behaviour which have been found to be related to downsizing in the present cohort $^{7}$ : physical work demands (one item, Standard Survey by Statistics Finland) ${ }^{33}$; aspects of job control, such as skill discretion (four item scale, Cronbach's $\alpha$ reliability 0.78 ) and opportunities to participate in decision making (three item scale; Cronbach's $\alpha 0.76)^{34}$; job insecurity (five item scale from the standard survey by Statistics Finland, Cronbach's $\alpha 0.87)^{33}$; and smoking (current smoker $v$ not). We also measured vigorous exercise ( $\geqslant 1$ hours a week of vigorous exercise) ${ }^{35}$ which has been associated with organisational restructuring in earlier studies. ${ }^{6}$

\section{OTHER VARIABLES}

Other variables, measured at baseline, were sex, age, and socioeconomic status, as indicated by income (median split for high $v$ low income; median incomes were 126000 and $114000 \mathrm{FIM} / \mathrm{year}$ for men and women, respectively).

\section{STATISTICAL ANALYSES}

Number of musculoskeletal sickness absence spells and person-years of follow up, as well as severity and sites of musculoskeletal pain were calculated for each employee. Poisson regression models were fitted to data with musculoskeletal sickness absence. ${ }^{56}$ Logistic regression analyses were conducted with severe musculoskeletal pain (a dichotomous variable). For several sites of musculoskeletal pain (a continuous variable), analysis of variance (ANOVA) was used.

The associations between downsizing and outcomes were adjusted for age, sex, and income. Ratios of rates of sickness absence and odds ratios (ORs) for severe musculoskeletal pain, and their $95 \%$ confidence intervals (95\% CIs), were calculated for major $(>18 \%)$ and intermediate $(8 \%-18 \%)$ versus minor $(<8 \%)$ downsizing. For number of sites of pain, we 
Table 1 Effect of downsizing on musculoskeletal problems adjusted for age, sex, and income

\begin{tabular}{lllll}
\hline $\begin{array}{l}\text { Indicator of musculoskeletal } \\
\text { problems }\end{array}$ & $\begin{array}{l}\text { Degree of } \\
\text { downsizing }\end{array}$ & $\begin{array}{l}\text { Crude } \\
\text { values }\end{array}$ & $\begin{array}{l}\text { Adjusted ratio / } \\
\text { difference (95\% CI) }\end{array}$ & $\begin{array}{l}\text { p Value for } \\
\text { linear trends }\end{array}$ \\
\hline Severe pain & Minor & 20 & 1.00 & \\
& $\begin{array}{l}\text { Intermediate } \\
\text { Major }\end{array}$ & 26 & $1.48(0.9$ to 2.4$)$ & \\
Sites of musculoskeletal pain† & 39 & $2.59(1.5$ to 4.5$)$ & $<0.001$ \\
& Minor & 2.77 & 0.00 & \\
& Intermediate & 3.31 & $0.29(-0.2$ to 0.7$)$ & \\
Major & 4.14 & $0.99(0.4$ to 1.6$)$ & $<0.001$ \\
& Minor & 4.8 & 1.00 & \\
& Intermediate & 16.6 & $2.11(1.7$ to 3.9$)$ & \\
& Major & 39.5 & $5.50(3.6$ to 7.6$)$ & $<0.001$
\end{tabular}

${ }^{\star}$ Crude values are percentages of cases. Adjusted ORs (95\% CIs) are reported.

tCrude values are mean numbers of sites. Adjusted differences between means (95\% CIs) are reported.

†Crude values are absence rates/100 person-years. Adjusted RRs (95\% CIs) are reported.

\The trend was dependent on income for sites of musculoskeletal pain $(\mathrm{p}=0.018)$ but otherwise independent of sex and income.

Table 2 Mean percentages (SEMs) of work characteristics and percentages (SE) of health related behaviour after downsizing adjusted for values before downsizing

\begin{tabular}{|c|c|c|c|c|}
\hline \multirow[b]{2}{*}{ Variable } & \multicolumn{3}{|c|}{ Degree of downsizing } & \multirow{2}{*}{$\begin{array}{l}p \text { Value for linear } \\
\text { trend } t\end{array}$} \\
\hline & Minor & Intermediate & Major & \\
\hline Physical demands & $64.0(0.7)$ & $65.4(0.6)$ & $72.8(0.9)$ & $<0.001$ \\
\hline Skill discretion & $73.9(0.8)$ & $69.7(0.6)$ & $68.0(1.0)$ & $<0.001$ \\
\hline Participation & $49.9(1.1)$ & $43.4(0.9)$ & $44.1(1.4)$ & $<0.001$ \\
\hline Job insecurity ${ }^{\star}$ & $11.3(0.3)$ & $13.1(0.2)$ & $14.5(0.4)$ & $<0.001$ \\
\hline Vigorous exercise & $12.0(1.9)$ & $10.9(1.5)$ & $13.0(2.5)$ & 0.826 \\
\hline Smoking & $14.9(1.6)$ & $16.9(1.2)$ & $20.7(2.1)$ & 0.029 \\
\hline
\end{tabular}

${ }^{\star}$ Measured only after downsizing and therefore no adjustment for job insecurity at baseline. $\dagger$ The trend was dependent on income in physical demands $(\mathrm{p}=0.005)$ and on sex in participation $(p=0.044)$ but otherwise independent of income and sex.

estimated differences between means (95\% CIs) after major and intermediate versus minor downsizing using the Dunnett test for multiple comparisons. $^{37}$

The effect of downsizing on work characteristics, treated as continuous variables, was studied by analyses of variance and its effect on dichotomous variables, the health related behaviour, by logistic regression. Means and ORs of these factors after downsizing were adjusted for their values before downsizing.

Linear trends and interactions with sex, income, and baseline health were tested in associations of downsizing with musculoskeletal problems and other variables.

To study how the association between downsizing and musculoskeletal problems contributed to changes in work characteristics and health related behaviour, a two step adjustment strategy was applied. ${ }^{78}$ Firstly, musculoskeletal problems after downsizing were adjusted for each characteristic age, income, sex, and work and health related behaviour before downsizing. Next, we included into these models the level of each characteristic after downsizing. A higher reduction in the effect of downsizing on musculoskeletal problems after the inclusion indicates a higher contribution as an explanatory factor. Tests were made separately for men and women and for employees with high and low income.

All the analyses were carried out for the entire cohort and for the initially healthy cohorts (those who had no musculoskeletal problems before downsizing). For logistic and Poisson models we used the GENMOD procedure and for analysis of variance the GLM procedure in the SAS program package.

\section{Results}

EFFECTS OF DOWNSIZING

There was a highly significant linear relation between downsizing and musculoskeletal problems across all outcomes (table 1). After adjustment for age, sex, and income, the ORs for severe musculoskeletal pain between major and minor downsizing and the corresponding rate ratio for musculoskeletal sickness absence were 2.6 and 5.5, respectively. Major downsizing was associated with about one symptom area more than minor downsizing. The relations did not significantly vary between sexes or income groups, except for the number of sites of musculoskeletal pain in which the trend was not significant for high income employees.

Associations between downsizing and characteristics of work and health related behaviour are shown in table 2. Major downsizing was related to increased levels of physical demands, job insecurity, and smoking, and decreased levels of skill discretion and participation in decision making. There were only two differences between sexes or income groups in these linear trends. The effect of downsizing on physical demands was stronger in low income employees than in high income employees and its effect on participation was stronger among women than among men. However, in all these cases the association was significant $(\mathrm{p}=0.038$ $<0.001$ ). Downsizing was not related to vigorous exercise.

\section{TEST OF EXPLANATORY FACTORS}

The test of explanatory factors involved all those characteristics of work and health related behaviour significantly associated with downsizing (tables 3-5). Although the association between downsizing and musculoskeletal problems did generally not differ between the sexes and income groups, it is possible that contributors to this association were not the same for these groups. For this reason, tests of explanatory factors were conducted separately for male, female, low income, and high income employees. We did not analyse vigorous exercise as it was not related to downsizing. Participation in decision making and smoking were associated with downsizing but they did not affect the relation between downsizing and musculoskeletal problems.

We have omitted the level "intermediate downsizing" from tables 3-5 because this information is redundant in supporting our conclusions. As the comparison between models 1 and 2 in table 3 shows, additional adjustment for physical demands after downsizing attenuated the association between downsizing and severe musculoskeletal pain in all groups. This indicates that increases in physical demands may partially underlie the association. Attenuation was $59 \%$ in men and $24 \%-$ $36 \%$ in other groups. Adjustment for covariates of skill discretion and job insecurity attenuated the association in women and low income employees. Simultaneous adjustment for all 
Table 3 OR (95\% CI) for severe musculoskeletal pain between major v minor downsizing by sex and income (in all cases the OR for minor downsizing was 1.00)

\begin{tabular}{|c|c|c|c|c|c|c|}
\hline \multirow[b]{3}{*}{ Population } & \multicolumn{6}{|l|}{ Covariate } \\
\hline & \multicolumn{2}{|l|}{ Physical demands } & \multicolumn{2}{|l|}{ Skill discretion } & \multicolumn{2}{|l|}{ fob insecurity } \\
\hline & Model 1 & Model 2 & Model 1 & Model 2 & Model 1 & Model 2 \\
\hline Men & 5.78 (1.1 to 26.2$)$ & $2.96(0.6$ to 14.9$)$ & $6.22(1.3$ to 28.8$)$ & $5.90(1.3$ to 27.8$)$ & $6.01(1.3$ to 27.0$)$ & 5.46 (1.2 to 25.8$)$ \\
\hline Women & $1.80(0.9$ to 3.6$)$ & $1.51(0.7$ to 3.1$)$ & $2.48(1.3$ to 4.8$)$ & $2.24(1.1$ to 4.4$)$ & $2.51(1.3$ to 4.8$)$ & $2.34(1.2$ to 4.5$)$ \\
\hline High income employees & $4.00(1.4$ to 11.5$)$ & 3.27 (1.1 to 9.7$)$ & $4.02(1.4$ to 11.4$)$ & $3.93(1.4$ to 11.1$)$ & $4.16(1.5$ to 11.7$)$ & $3.86(1.3$ to 11.2$)$ \\
\hline Low income employees & $2.26(0.8$ to 6.1$)$ & $1.92(0.7$ to 5.4$)$ & $3.43(1.3$ to 9.1$)$ & $2.85(1.1$ to 7.7$)$ & $3.20(1.2$ to 8.4$)$ & $2.91(1.1$ to 7.7$)$ \\
\hline
\end{tabular}

Model 1 is adjusted for age, income, and covariate before downsizing, with the exception of job insecurity which was not measured at baseline. Model 2 is additionally adjusted for covariate at the end of downsizing.

Italics are used to point out attenuation $>10 \%$ in the effect of major downsizing in model 2 compared with that in model 1 . A higher attenuation indicates a higher contribution of the covariate as an explanatory factor.

Table 4 Difference in mean (95\% CI) number of sites of musculoskeletal pain between major $v$ minor downsizing by sex and income (in all cases the mean difference for minor downsizing was 0.00)

\begin{tabular}{|c|c|c|c|c|c|c|}
\hline \multirow[b]{3}{*}{ Population } & \multicolumn{6}{|l|}{ Covariate } \\
\hline & \multicolumn{2}{|l|}{ Physical demands } & \multicolumn{2}{|l|}{ Skill discretion } & \multicolumn{2}{|l|}{ fob insecurity } \\
\hline & Model 1 & Model 2 & Model 1 & Model 2 & Model 1 & Model 2 \\
\hline Men & $1.07(-0.2$ to 1.1$)$ & $0.84(-0.5$ to 2.2$)$ & $0.97(-0.4$ to 2.3$)$ & $0.86(-0.5$ to 2.1$)$ & $1.12(-0.2$ to 2.4$)$ & $1.05(-0.3$ to 2.4$)$ \\
\hline Women & $0.51(-0.2$ to 1.2$)$ & $0.29(-0.4$ to 1.0$)$ & $0.80(0.1$ to 1.5$)$ & $0.80(0.1$ to 1.5$)$ & $0.91(0.2$ to 1.6$)$ & $0.87(0.2$ to 1.5$)$ \\
\hline High income employees & $1.13(0.3$ to 2.0$)$ & $0.89(-0.0$ to 1.8$)$ & $1.42(0.6$ to 2.3$)$ & $1.42(0.5$ to 2.3$)$ & $1.55(0.7$ to 2.4$)$ & $1.53(0.7$ to 2.4$)$ \\
\hline Low income employees & $0.25(-0.8$ to 1.3$)$ & $0.11(-0.9$ to 1.2$)$ & $0.27(-0.8$ to 1.3$)$ & $0.21(-0.9$ to 1.3$)$ & $0.31(-0.8$ to 1.4$)$ & $0.18(-0.9$ to 1.3$)$ \\
\hline
\end{tabular}

Explanations as in table 3.

Table 5 Ratio (95\% CI) of rates of musculoskeletal sickness absence between major $v$ minor downsizing by sex and income (in all cases the rate ratio for minor downsizing was 1.00)

\begin{tabular}{|c|c|c|c|c|c|c|}
\hline \multirow[b]{3}{*}{ Population } & \multicolumn{6}{|l|}{ Covariate } \\
\hline & \multicolumn{2}{|l|}{ Physical demands } & \multicolumn{2}{|l|}{ Skill discretion } & \multicolumn{2}{|l|}{ fob insecurity } \\
\hline & Model 1 & Model 2 & Model 1 & Model 2 & Model 1 & Model 2 \\
\hline Men & $5.62(2.9$ to 10.8$)$ & $5.96(2.9$ to 12.3$)$ & $5.16(2.7$ to 10.0$)$ & $5.31(2.7$ to 10.4$)$ & $5.96(3.1$ to 11.5$)$ & 5.18 (2.6 to 10.2$)$ \\
\hline Women & 6.40 (3.1 to 13.4$)$ & $5.30(2.5$ to 11.2$)$ & 7.49 (3.6 to 15.5$)$ & 7.08 (3.4 to 14.7$)$ & $8.22(4.0$ to 16.9$)$ & 8.08 (3.9 to 16.6$)$ \\
\hline High income employees & $5.26(2.4$ to 11.7$)$ & $5.68(2.4$ to 13.3$)$ & $5.97(2.7$ to 13.2$)$ & $6.64(3.0$ to 14.9$)$ & $6.84(3.1$ to 15.0$)$ & 7.39 (3.3 to 16.7$)$ \\
\hline Low income employees & $5.33(2.6$ to 11.0$)$ & 4.44 (2.1 to 9.3$)$ & $5.69(2.8$ to 11.7$)$ & $5.26(2.6$ to 10.9$)$ & $6.17(3.0$ to 12.6$)$ & 5.88 (2.9 to 12.0$)$ \\
\hline
\end{tabular}

Explamations as in table 3.

these covariates reduced the association between downsizing and musculoskeletal pain by $60 \%$ and $54 \%$ in women and low income employees, respectively. Although adjustment for job insecurity also affected the association in men, controlling simultaneously for physical demands and job insecurity did not lead to extra attenuation in the association.

Adjustment for physical demands attenuated the association between downsizing and number of sites of musculoskeletal pain more than $20 \%$ in all groups (table 4). Adjustment of skill discretion reduced this association in men and adjustment of job insecurity in low income employees. As can be seen in table 5, adjustment for physical demands affected the association between downsizing and musculoskeletal sickness absence only in women and low income employees, leading to $17 \%-20 \%$ reductions in the association. In men, adjustment for job insecurity also attenuated this association.

INITIALLY HEALTHY POPULATION

To explore whether downsizing was associated with incidence of musculoskeletal problems, we conducted analyses for initially healthy subcohorts. At baseline, there were 604 employees with no severe musculoskeletal pain, 353 employees with no sites of musculoskeletal pain, and 686 employees with no musculoskeletal sickness absence. There was a linear trend across all three indicators of musculoskeletal problems $(p<0.01)$. After adjustment for age, sex, and income, OR for severe musculoskeletal pain between major and minor downsizing and the corresponding rate ratios (RRs) for musculoskeletal sickness absence were 2.25 (95\% CI 1.1 to 4.6 ) and 3.34 (95\% CI 2.1 to 5.4), respectively. Major downsizing was associated with over a half symptom area more than minor downsizing.

Downsizing was also associated with changes in each characteristic of work but not with changes in health related behaviour. In most cases, tests of explanatory factors led to results similar to those for all participants. The only exceptions were that job insecurity did not contribute to the relation between downsizing and severe pain in men and that decreased skill discretion did not contribute to this relation in women.

\section{Discussion}

This longitudinal study took advantage of a natural experiment by following up the same people before any rumour of downsizing and after downsizing. Our data provide robust evidence that downsizing is associated with increased musculoskeletal problems. This has already been found for musculoskeletal sickness absence, but the evidence from self reporting is 
new and important, as they are not work measures. Also, the present study provides new information about mechanisms linking downsizing with musculoskeletal problems.

The effect of downsizing on musculoskeletal problems in those remaining in employment was obvious across the three different indicators of musculokeletal problems, in men and women and also in the initially healthy subcohort. Downsizing was associated with reported severity and sites of musculoskeletal pain immediately after staff reductions. The association was even stronger relative to musculoskeletal sickness absences measured for an extended period covering two subsequent years after downsizing. Sickness absence is considered as one of the best measures of musculoskeletal disability in working populations. ${ }^{39}$ In this study, all the spells of musculoskeletal sickness absence were certified by a doctor.

In low income employees and women, increases in physical demands accounted for from one fifth to over one third of the effect of downsizing on musculoskeletal problems across all the outcomes under study. In male and high income employees, increased physical demands contributed to the association between downsizing and subjective experiences of musculoskeletal problems but not to sickness absence. Increased physical demands probably imply pathophysiological mechanisms related to heightened exposure to physical risk factors such as lifting, twisting, and bending..$^{40-43}$ Low income employees (cleaners, nursing auxiliaries, and kitchen workers) have physically strenuous work with high exposure to such physical risk factors for musculoskeletal problems, ${ }^{44}{ }^{45}$ and a higher proportion of these employees are women than men. This may partially explain the more significant role of physical demands in women.

Results for the other explanatory factors were not as robust as those related to physical demands. Reduction of skill discretion partially explained the effects of downsizing on self reported musculoskeletal problems but not on sickness absence or in high income employees. The mechanism by which skill discretion may influence musculoskeletal problems is not known. It is possible that it involves control over physical demands at work. ${ }^{8446}$ This is probably not more than a partial explanation of the present results because the combined effect of physical demands and skill discretion clearly exceeded that found related to physical demands alone.

Job insecurity may produce a stress response increasing muscle tension, a factor with the potential to increase musculoskeletal problems. ${ }^{12} 47$ In men with pre-existing disease, job insecurity played a more pronounced part than in women. The contribution of job insecurity may have been stronger if those with nonpermanent contracts had been included in the study or if the downsizing had affected permanent employees more than it did. ${ }^{346}$ In Raisio, only employees without permanent contracts of employment lost jobs. ${ }^{49}$ As usual in the public sector in Finland and other countries, staff numbers were reduced through retirement, by not filling vacancies, and by not hiring cover for those absent from work. ${ }^{49}$

We found no support for increased smoking and vigorous exercise as behavioural pathways linking downsizing and musculoskeletal problems within the time frame of this study. Major downsizing was associated with increased prevalence of smoking, supporting earlier findings on organisational restructuring. ${ }^{25}$

METHODOLOGICAL CONSIDERATION

To reflect accurately the true changes in days worked, our measure of downsizing took into account reductions due to sickness absence as well as other days legitimately spent away from work, finishing work, and new work contracts. Excluding sickness absence from the measure of downsizing yielded similar estimates for the effect of downsizing on musculoskeletal sickness absence (excess risk after major downsizing was 5.6 (95\% CI 3.7 to 8.6$)$ ). Relations between exposure and outcome are therefore unlikely to have overestimated the effects of downsizing. Moreover, the significant associations between downsizing and self reported musculoskeletal pain were unaffected by any such possible confounding.

Although several potential pathways were identified, almost half of the relation between downsizing and musculoskeletal problems remained unexplained. This may be due to several reasons. Firstly, the measurement of the potential explanatory factors was much more open to error than the measurement of downsizing and musculoskeletal sickness absence, which were both derived from daily based registered data, although the two other measures of musculoskeletal problems were similarly self reports. Secondly, the relation between downsizing and musculoskeletal problems may be partially explained by factors not measured in this study, such as increased sleeping problems, lifting, and carrying. Thirdly, it is not clear whether inability to identify explanatory factors of downsizing among the sample of high income employees reflect true differences between socioeconomic groups or practical constrains of the data. Major downsizing was not as common in this group as among low income respondents. However, a significant interaction between downsizing and income on physical demands and musculoskeletal pain indicates that the effects of downsizing may vary by socioeconomic position.

\section{Conclusions}

As a conclusion, this natural experiment provides evidence of an association between downsizing and the development of musculoskeletal problems, and identifies potential linking mechanisms. We showed that downsizing significantly increases risk of musculoskeletal problems among those who remain in employment. Concomitant increase in physical work demands contributed to this risk, particularly in women and low income employees. Reduction of skill discretion was also a potential explanatory factor but only in relation to self 
reported indicators of musculoskeletal problems. In men, job insecurity played a notable part among those with musculoskeletal problems before downsizing. If indeed downsizing continues to be a significant trend within industrialised countries for the foreseeable future, as has been suggested, ${ }^{1}$ then those making decisions should be aware of these negative consequences of this managerial strategy.

MK was the principal investigator and together with JV designed and conducted the study and wrote the paper. JEF and
HH contributed to the writing of the paper, helped in the data $\mathrm{HH}$ contributed to the writing of the paper, helped in the data
analysis, and advised in the interpretation and presentation of analysis, and advised in the interpretation and presentation of the results. JP developed the downsizing measure and helped in
data analysis. MK is supported by the Academy of Finland data analysis. $\mathrm{MK}$ is supported by the Academy of Finland (project No 44968), JV by the Finnish Work Environment
Fund, JEF by the Economic and Social Research Council (L Fund, JEF by the Economic and Social Research Council (L
128251046 ), and HH by a Public Health Career Scientist Award from the Department of Health during the preparation of this work. We thank Dr Marja Lampio from the occupational health-care unit in Raisio; and all participating municipal employees.

1 Hurrell JJ. Editorial. Am F Public Health 1998;88:1012-3.

2 Cascio WF. Learning from outcomes: financial experiences of 311 firms that have downsized. In: MK Gowing, JD Kraft, JC Quick, eds. The new organizational reality. Washington: American Psychological Association, 1998: 55-70

3 Beale N, Nethercott S. Certificated sickness absence in industrial employees threatened with redundancy. $B M^{\mathcal{F}}$ industrial employe

4 Ferrie JE, Shipley MJ, Marmot MG, et al. Health effects of anticipation of job change and non-employment: longitudinal

5 Vahtera J, Kivimäki M, Pentti J. Effect of organisational downsizing on health of employees. Lancet 1997;350:11248.

6 Ferrie JE, Shipley MJ, Marmot MG, et al. An uncertain future: the health effects of threats to employment security in white-collar men and women. Am f Public Health 1998 88:1030-6.

7 Kivimäki M, Vahtera J, Pentti J, et al. Factors underlying the effect of organisational downsizing on the health of employees: a longitudinal cohort study of changes in work, social relations and health behaviours. BMf 2000;320:9715.

8 Klaukka T, Sievers K, Takala J. Epidemiology of rheumatic disease in Finland in 1964-76. Scand F Rheumatol 1982;47: $5-13$.

9 Office of Population Censuses and Surveys, Martin J, Melzer $\mathrm{H}$, et al. OPCS surveys of disability in Great Britain, report 1 (prevalence of disability among adults). London: The Stationery Office, 1988

10 Feeney A, North F, Head J, et al. Socioeconomic and sex differentials in reason for sickness absence from the Whitehall II study. Occup Environ Med 1998;55:91-8.

11 Guo H-R, Tanaka S, Halperin WE, et al. Back pain prevalence in US industry and estimates of lost workdays. Am $\mathcal{F}$ Public Health 1999;89:1029-35.

12 Hales TR, Bernard BP. Epidemiology of work related musculoskeletal disorders. Occup Disorder Management 1996;27:679-709.

13 Leijon M, Hensing G, Alexanderson K. Gender trends in sick-listing with musculoskeletal symptoms in a Swedish
county during a period of rapid increase in sickness absence. Scand F Soc Med 1998;26:204-13.

14 Linton SJ. An overview of psychosocial and behavioral factors in neck-and-shoulder pain. Scand $\mathcal{F}$ Rehabil Med 1992; tors in neck- $67-78$.

15 Bongers PM, de Winter CR, Kompier MAJ, et al. Psychosocial factors at work and musculoskeletal disease. Scand $\mathcal{F}$ cial factors at work and musculoskelet

16 Houtman ILD, Bongers PM, Smulders PGW, et al. Psychosocial stressors at work and musculoskeletal problems. Scand $\mathcal{f}$ Work Environ Health 1994;20:139-45.

17 Leino PI, Hänninen V. Psychosocial factors at work in relation to back and limb disorders. Scand $\mathcal{F}$ Work Environ Health 1995;21:134-42.

18 Skov T, Borg V, Orhede E. Psychosocial and physical risk factors for musculoskeletal disorders of the neck, shoulders, and lower back in salespeople. Occup Environ Med 1996;53:351-6.

19 Hemingway H, Shipley M, Stansfeld S, et al. Are risk factors for atherothrombotic disease associated with back pain sickness absence? The Whitehall II study. F Epidemiol Community Health 1999;53:197-203.

20 Toomingas A, Theorell T, Michélsen H, et al. Associations between self-rated psychosocial work conditions and musculoskeletal symptoms and signs. Scand 7 Work Environ Health 1997:23:130-9.

21 Hemingway H, Shipley MJ, Stansfeld S, et al. Sickness absence from back pain, psychosocial work characteristics and employment grade among office workers. Scand $\mathcal{F}$ Work Environ Health 1997;23:121-9.

22 Stansfeld S, Head J, Ferrie J. Short-term disability, sickness absence, and social gradients in the Whitehall II study. Int f Law Psychiatry 1999;22:425-39.

23 Elovainio M, Sinervo T. Psychosocial stressors at work, psychosocial stress and musculoskeletal symptoms in the care for the elderly. Work Stress 1997;11:351-62.

24 Ferrie JE Shipley MJ, Marmot MG, et al. The health effects of major organisational change and job insecurity. Soc Sci Med 1998;46:243-54.

25 Ferrie JE, Shipley MS, Marmot MG, et al. Job insecurity in white-collar workers: towards an explanation of associawhite-collar workers: towards an explanation of associa-
tions with health. $\mathcal{O}$ Occup Health Psychol 2001;2:26-42.

26 Marmot MG, Feeney A, Shipley M, et al. Sickness absence as a measure of health status and functioning: from the UK Whitehall II study. F Epidemiol Community Health 1995;49: 124-30

27 Statistical yearbook of Finland. Helsinki: Statistics Finland, 1998.

28 Million R, Hall W, Nilsen $\mathrm{KH}$, et al. Assesment of the progress of the back-pain patient 1981 Volvo Award in Clinical Science. Spine 1982;7:204-12.

29 Vahtera J, Uutela A, Pentti J. The effects of objective job demands on registered sickness absence spells: do personal, social, and job-related resources act as moderators? Work Stress 1996;19:286-308.

30 Kuorinka I, Jonsson B, Kilbom A, et al. Standardised nordic questionnaires for the analysis of musculoskeletal sympquestionnaires for the analysis
toms. Appl Ergon $1987 ; \mathbf{1 8}: 233-7$.

31 Dickinson CE, Campion K, Foster AF, et al. Questionnaire development: an examination of the Nordic musculoskeletal questionnaire. Appl Ergonomics 1992;23:197-201.

32 World Health Organisation. International classification of diseases, 1977 revision. Geneva: WHO, 1977.

33 Lehto A-M. Työelämän laatu ja tasa-arvo tuotannossa (Ouality of working life and equity). Helsinki: Statistics Finland, 1991.

34 Kivimäki M, Vahtera J, Thomson J, et al. Psychosocial factors predicting employee sickness absence during economic decline. F Appl Psychol 1997;82:858-72.

35 Kujala UM, Kaprio J, Sarna S, et al. Relationship of leisuretime physical activity and mortality. FAMA 1998;279:4404.

36 SAS Institute. SAS technical report P-243, SAS/STAT software: the GENMOD procedure, release 6.09. Cary, NC: SAS Institute, 1993.

37 Winer BJ. Statistical principles in experimental design. London: McGraw-Hill, 1971

38 Baron RM, Kenny DA. The moderator-mediator variable distinction in social psychological research: conceptual, strategic, and statistical considerations. 7 Personality Soc Psychol 1984;51:1173-82.

39 Spitzer WO, LeBlanc FE, Dupuis M. Scientific approach to the assessment and management of activity related spinal disorders: a monograph for clinicians: report of the Quebec Task Force on Spinal Disorders. Spine 1987;12:1-59.

40 Theorell T, Harms-Ringdahl K, Ahlberg-Hulten G, et al. Psychosocial job factors and symptoms from the locomotor system - a multicausal analysis. Scand f Rehabil Med 1991; 23:165-73.

41 Kuorinka I, Forcier L, eds. Work related musculoskeletal disorders: a reference book for prevention. London: Taylor and Francis, 1995

42 Bernard BP. Musculoskeletal disorders and workplace factors: a critical review of epidemiologic evidence for work related musculoskeletal disorders of the neck, upper extremity, and low back. Washington, DC: US Department of Health and Human Services, Public Health Service, Center for Disease Control, and National Institute of Occupational Safety and Health, 1997

43 Wickström GJ, Pentti J. Occupational factors affecting sick leave attributed to low back pain. Scand $\mathcal{F}$ Work Environ Health 1998;24:145-52.

44 Skovron M. Epidemiology of low back pain. Ballerie's Clinical Rheumatology 1992;6:559-73.

45 Vahtera J, Pentti J. Employees in the storm of economy: development of psychosocial work environment between 1990-7. ment of psychosocial work environment between 1990-7.

46 Walsh K, Varnes N, Osmond C, et al. Occupational causes of low back pain. Scand $\mathcal{F}$ Work Environ Health 1989;15:549.

47 Lundberg U, Kadefors R, Melin B, et al. Psychophysiological stress and EMG activity of the trapezius muscle. Int $\mathcal{F}$ Behav Med 1994;1:354-70.

48 Cobb S, Kasl SV. Termination: the cconsequences of job loss. Cincinatti: National Institute for Occupational Safety and Health, 1977

49 Kivimäki M, Vahtera J, Griffiths A, et al. Sickness absence and organizational downsizing. In: RJ Burke, CL Cooper, eds. The organization in crisis: downsizing, restructuring, and privatization. Oxford: Blackwell, 2000:78-94. 